\title{
Desenvolvimento ponderal de bezerras desmamadas em pastejo de Brachiaria decumbens com suplementação protéica e energética
}

\author{
José Luiz Viana Coutinho Filho(1) ${ }^{(1)}$ élio Luiz Justo(1) e Roberto Molinari Peres(1)
}

\begin{abstract}
(1)Agência Paulista de Tecnologia dos Agronegócios (APTA), Unidade de Pesquisa e Desenvolvimento, Rodovia Washington Luiz, Km 445, Caixa Postal 1013, CEP 14025-990 São José do Rio Preto, SP. E-mail: coutinho@aptaregional.sp.gov.br, celiojusto@aptaregional.sp.gov.br, molinari@aptaregional.sp.gov.br
\end{abstract}

Resumo - Foi avaliado o efeito da suplementação a pasto, com concentrados fornecidos durante o ano (períodos de seca e águas), sobre o desenvolvimento ponderal de bezerras desmamadas. Foram utilizadas 36 bezerras da raça Santa Gertrudis, com média inicial de idade de 290 dias, média de peso vivo de 194 kg, mantidas em pasto de Brachiaria decumbens, distribuídas em um delineamento inteiramente casualizado, com dois tratamentos e 18 repetições. Foi oferecida mistura mineral o ano todo, ou suplemento com maior nível de proteína degradável na seca, e não-degradável nas águas. Os resultados obtidos para a média diária de ganho de peso vivo indicaram uma diferença significativa entre os tratamentos. $\mathrm{O}$ ganho de peso vivo, durante o ano, para o lote testemunha, foi de $0,504 \mathrm{~kg}_{\text {animal }}{ }^{-1} \mathrm{dia}^{-1} \mathrm{e}$, para o lote suplementado foi de $0,561 \mathrm{~kg}$. No período de seca, o ganho de peso vivo foi significativamente maior para os animais suplementados e, no período das águas não ocorreu diferença. A suplementação a pasto não apresentou vantagens bioeconômicas para se recomendar o seu uso. Nos dois tratamentos as bezerras alcançaram média de peso limite, para primeira cobertura, com idade próxima a 14 meses.

Termos para indexação: bezerras de corte, ganho de peso, pasto, proteína degradável, suplemento.

\section{Ponderal performances of calves grazing Brachiaria decumbens and supplemented with protein and energetic diets}

\begin{abstract}
The concentrate supplementation effect upon ponderal performance of calves during the year (dry and wet seasons) was evaluated. Thirty-six Santa Gertrudis calves averaging $194 \mathrm{~kg}$ of live weight, with 290 days of age, grazing Brachiaria decumbens pasture, were used in a complete randomized design. The following supplements have been added ad libitum, fed during the experimental period: mineral mix, supplement based on degradable protein, during dry season, and supplement based on non-degradable protein (escape protein), during wet season. Results on average daily gain demonstrated a significant difference between treatments. The average daily gains were 0.504 and $0.561 \mathrm{~kg}$ animal ${ }^{-1} \mathrm{day}^{-1}$ for the non-supplemented group (control group, fed mineral mix only), and supplemented group, respectively. During dry season, supplemented calves showed significantly higher average daily gain, and during wet season there was no difference. Pasture supplementation did not present bioeconomic advantage, then its use could not be recommended. In both treatments, calves reached the average weight limit, for first mating, at nearly 14 months of age.
\end{abstract}

Index terms: beef calves, weight gain, pasture, degradable protein, supplement.

\section{Introdução}

As condições climáticas, nos trópicos, promovem uma ampla variação anual da quantidade e qualidade da forrageira das pastagens, que é a principal causa das idades avançadas de abate e das elevadas idades da primeira cobertura de bovinos de corte.

No Brasil, as pastagens de Brachiaria decumbens são as principais responsáveis pela produção de bovinos de corte, entretanto, resultados de pesquisas indi- cam que essa gramínea não tem potencial para atender às exigências nutricionais, para uma produção máxima no decorrer do ano (Euclides et al., 1997), a qual ficaria dependente de uma suplementação alimentar.

Minson (1990) afirmou que forragem de baixa qualidade ( $\mathrm{PB}<7 \%$ ), que é usual na seca, limitaria a atividade dos microrganismos no rúmen e, conseqüentemente, afetaria a digestibilidade e consumo da mesma, o que implicaria pior desempenho animal. Entre os pesquisadores que estudaram a influência do nível de proteína 
degradável, no desempenho de ruminantes, Hoover \& Miller (1992) afirmaram que a eficiência dos microrganismos do rúmen é máxima, quando a matéria seca ingerida contém entre $10 \%$ e $13 \%$ de proteína degradável. Poppi \& Mc Lennan (1995) acreditam, também, que apesar de não ocorrer falta de proteína na época das chuvas, pode haver uma resposta positiva à suplementação protéica (proteína não degradável no rúmen).

Milton et al. (1997) relataram que o uso de proteína não degradável no rúmen para a terminação de novilhos alimentados com milho, tem pouco valor, provavelmente em função da deficiência no atendimento dos requisitos em proteína metabolizável, por intermédio da proteína do milho, que escapa da degradação e da proteína microbiana produzida.

A utilização de proteína não degradável no rúmen (PNDR), na alimentação de bovinos, no sentido de melhorar o desempenho tanto em condições de pasto na época das águas, como de confinamento, já vem sendo estudada há mais de uma década. Poppi \& McLennan (1995) afirmaram que suplementos energéticos e suplementos com altos níveis de PNDR seriam benéficos, para incrementar o ganho de peso em condições tropicais.

De maneira semelhante à proteína, o fornecimento de um suplemento energético para ruminantes em pastejo, segundo Caton \& Dhuyvetter (1997), geralmente melhora o ganho de peso vivo e a condição corporal (score), mas, na maioria das vezes, diminui a ingestão de forragem e a digestibilidade; baixos níveis de suplementação energética podem aumentar os valores desses parâmetros.

Paulino et al. (1982) afirmaram que, de um modo geral, uma suplementação protéica teria condições de satisfazer as deficiências de proteína e de energia dos bovinos mantidos em pastagens, mas que a suplementação energética não supriria os requisitos protéicos.

A suplementação de bovinos a pasto tem apresentado resultados variáveis, e requer, portanto, mais dados.

O objetivo deste trabalho foi avaliar o manejo da suplementação protéica e energética para animais em condições de pasto, durante os períodos de seca e águas, em relação ao desenvolvimento de bezerras de corte.

\section{Material e Métodos}

O experimento foi conduzido de 1998 a 1999, na Unidade de Pesquisa e Desenvolvimento de Mirassol, pertencente ao Pólo Regional de Desenvolvimento Tecnológico dos Agronegócios do Centro Norte (APTA - Secretaria da Agricultura e Abastecimento do Estado de São Paulo), localizada na região Noroeste do Estado, a $20^{\circ} 48^{\prime} \mathrm{S}$ e $49^{\circ} 23^{\prime} \mathrm{W}$, e a $468 \mathrm{~m}$ de altitude. Segundo Köppen, essa região apresenta clima do tipo Aw, com estação chuvosa no verão, seguida de tempo ameno e seco no inverno. A precipitação média anual, nos últimos 11 anos, 1993 a 2003, foi de $1.468 \mathrm{~mm}$. O solo é identificado como Podzólico Vermelho-Amarelo distrófico, com relevo levemente ondulado.

Foram avaliados dois tipos de suplementação: um só de mistura mineral (MM), e outra protéica e energética (SPE), tendo sido priorizado, na época seca, o nível de proteína degradável no rúmen (PDR) e, nas águas, o de proteína não-degradável (PNDR), num delineamento inteiramente casualizado, com 2 tratamentos e 18 repetições. Na seca, a fonte específica de PDR foi a uréia e, nas águas, a fonte específica de PNDR foi a farinha de peixe.

A mistura mineral oferecida foi comercial, recomendada para a categoria animal utilizada no experimento, com a seguinte composição por kg do produto: $126 \mathrm{~g}$ de Na, 194 g de Cl, 88 g de P, 120 g de Ca, 10,5 g de Mg, 1,8 g de Fe, 4 g de Zn, 1,5 g de Cu, 1,3 g de Mn, 0,055 g de Co, 0,075 g de I, 0,015 g de Se. Os suplementos oferecidos, nas duas épocas do ano, estão descritos na Tabela 1. Eles foram formulados de modo que sua composição parcial, na época da seca, fosse $43 \%$ de proteína bruta (PB) $(83,4 \%$ de PDR) e $68 \%$ de nutrientes digestíveis totais (NDT) e, nas águas, 39,5\% de PB (43\% de PNDR) e $65,7 \%$ de NDT. Os suplementos foram oferecidos ad libitum; por intermédio de ingredientes reguladores, previa-se um consumo de suplemento protéico e energético de aproximadamente $800 \mathrm{~g}_{\text {animal }}{ }^{-1} \mathrm{dia}^{-1}$.

Tabela 1. Composição (\%) dos suplementos.

\begin{tabular}{lcc}
\hline Ingredientes & \multicolumn{2}{c}{ Épocas } \\
\cline { 2 - 3 } & Seca & Águas \\
\hline Farelo de soja & 40,0 & 63,5 \\
Polpa de citrus & 43,5 & - \\
Uréia & 6,8 & - \\
Sulfato de amônio & 1,2 & - \\
Sal comum & 5,5 & 14,5 \\
Mistura mineral & 3,0 & 3,0 \\
Farinha de peixe & - & 10,9 \\
Farinha de trigo & - & 7,9 \\
Rumensin & - & 0,2 \\
\hline
\end{tabular}


Foram utilizadas 36 bezerras desmamadas, da raça Santa Gertrudis, com aproximadamente 290 dias de idade e $194 \mathrm{~kg}$ de peso vivo, todas oriundas do mesmo rebanho e do mesmo manejo, que permaneceram sob pastejo durante todo o período experimental.

Um pasto de Brachiaria decumbens foi dividido em dois piquetes de 8,5 ha cada, com a lotação inicial de aproximadamente uma UA ha-1. Cada piquete possuía um cocho de concreto coberto, com comprimento que disponibilizava espaço de $50 \mathrm{~cm}_{\text {animal }}{ }^{-1}$. Foi realizado um rodízio dos animais nos piquetes a cada 14 dias, para minimizar o efeito das pastagens. Os pastos foram manejados, a fim de não permitir que a altura fosse reduzida a menos de $20 \mathrm{~cm}$. No final do período das águas, anterior ao período experimental, foi realizado um manejo para aumentar a disponibilidade de MS para a época seca, de 3.500 a $4.000 \mathrm{~kg} \mathrm{ha}^{-1}$.

Os animais foram pesados no início do experimento, no mês de julho, e a cada 28 dias, após jejum total de 18 horas. Nos dias de pesagens, eram retiradas as sobras do suplemento e da mistura mineral para o cálculo do consumo médio nos períodos. Foram realizadas observações parciais a respeito do hábito de consumo do suplemento durante alguns períodos de pastejo.

Os dados foram submetidos à análise de variância e, para as comparações entre as médias, utilizou-se o teste de Tukey a $5 \%$ de probabilidade.

\section{Resultados e Discussão}

A precipitação pluviométrica no decorrer do experimento foi de $431 \mathrm{~mm}$ no período de seca, julho a outubro, e $1.178 \mathrm{~mm}$ no período de águas, novembro a fevereiro. Pode-se considerar que a seca foi amena, pois os meses de agosto (107 $\mathrm{mm})$ e outubro $(219 \mathrm{~mm})$ foram atípicos, propiciando, assim, uma condição de pasto satisfatória para a época.

O consumo médio diário dos suplementos, de nutrientes e da mistura mineral estão apresentados na Tabela 2, e os valores referentes ao peso vivo e ganho de peso, na Tabela 3. O consumo da mistura mineral comercial, pelos animais do lote que não recebeu suplementação, foi de 71 e $74 \mathrm{~g}_{\text {animal }}{ }^{-1} \mathrm{dia}^{-1}$, para seca e águas, respectivamente, as quais podem ser consideradas acima do esperado, em razão da categoria animal utilizada.

Não foi realizada análise estatística do consumo, pois, os animais foram alimentados em grupo.

Considerando-se o ganho de peso médio diário, nos dois períodos avaliados, a diferença de $57 \mathrm{~g}$ a favor dos suplementados foi significativa; mas a diferença entre os pesos finais, $302 \mathrm{~kg}$ e $290 \mathrm{~kg}$, não qualifica a suplementação em termos de resultados biológicos e econômicos no sistema de produção, com vistas à melhoria no desempenho ponderal e reprodutivo.

Tabela 2. Consumo diário médio dos suplementos e dos nutrientes, nas épocas de suplementação.

\begin{tabular}{|c|c|c|c|c|}
\hline \multirow[t]{2}{*}{ Ingestões } & \multicolumn{2}{|c|}{ Seca } & \multicolumn{2}{|c|}{ Águas } \\
\hline & $\mathrm{SPE}^{(1)}$ & $\mathrm{MM}^{(2)}$ & SPE & MM \\
\hline Suplemento $\left(\mathrm{kg}\right.$ animal $\left.{ }^{-1}\right)$ & 0,969 & 0,071 & 0,731 & 0,074 \\
\hline$\% \mathrm{PV}$ & 0,435 & - & 0,265 & - \\
\hline PB $\left(\right.$ g animal $\left.^{-1}\right)$ & 375 & - & 255 & - \\
\hline $\operatorname{PDR}\left(\mathrm{g}\right.$ animal $\left.^{-1}\right)$ & 310 & - & 154 & - \\
\hline PNDR ( $\left.g_{\text {animal }}^{-1}\right)$ & 65 & - & 101 & - \\
\hline NDT $\left(g_{\text {animal }}{ }^{-1}\right)$ & 594 & - & 425 & - \\
\hline Eficiência de ganho ${ }^{(2)}$ & 0,69 & - & 0,621 & - \\
\hline
\end{tabular}

Tabela 3. Peso vivo médio e ganho em peso diário, de bezerras desmamadas da raça Santa Gertrudis, suplementadas e nãosuplementadas, nas épocas de seca e de águas.

\begin{tabular}{|c|c|c|c|c|}
\hline \multirow{2}{*}{ Peso vivo (kg) } & \multicolumn{4}{|c|}{ Tratamento } \\
\hline & $\mathrm{CS}^{(1)}$ & $\mathrm{SS}^{(2)}$ & Seca & Águas \\
\hline Início da seca & 195 & 194 & - & - \\
\hline Final da seca e início das águas & 251 & 244 & - & - \\
\hline Final das águas & 302 & 290 & - & - \\
\hline \multicolumn{5}{|c|}{ Ganho médio diário de peso (GPV) $(\mathrm{kg})^{(3)}$} \\
\hline Suplementação & $0,561 *$ & $0,504 *$ & - & - \\
\hline Época & - & - & $0,635 * *$ & $0,430 * *$ \\
\hline Seca & $0,669^{*}$ & $0,602 *$ & - & - \\
\hline Águas & $0,454 *$ & $0,406^{*}$ & - & - \\
\hline Suplementados & - & - & $0,669 * *$ & $0,454 * *$ \\
\hline Não-suplementados & - & - & $0,602 * *$ & $0,406 * *$ \\
\hline
\end{tabular}


São poucos os trabalhos que abrangem os períodos de seca e águas, conjuntamente, com um mesmo grupo de animais. Na pesquisa de Thiago \& Silva (2002) foram avaliados 4 níveis de suplementação, 0, 500, 1000 e $2000 \mathrm{~g} \mathrm{dia}^{-1}$, nos dois períodos do ano, mas com reagrupamento dos animais no início das águas. Os autores concluíram que o potencial das pastagens tropicais, para ganho de peso, pode ser melhorado por intermédio de manejo e suplementação alimentar, com melhor resultado na época de seca; o ganho compensatório seria uma possível explicação. No presente trabalho não foi identificada essa característica, pois ao final da seca, a diferença média de peso a favor dos animais suplementados, era de aproximadamente 7 kg e, após o período das águas era de $12 \mathrm{~kg}$. Pela Tabela 2, pode-se observar que o nível de consumo do concentrado, em relação ao peso vivo (PV) dos animais, foi abaixo de $0,5 \%$, o que, segundo Lalman \& Gill citados por Grandini (2001), não implicaria efeito substitutivo; assim, a ingestão de grãos, na proporção de $0,25 \%$ a $0,5 \%$ do PV, não afetaria ou provocaria um pequeno aumento na ingestão de matéria seca e na digestibilidade da forragem, e poderia proporcionar um pequeno aumento no desempenho animal.

No trabalho de Thiago \& Silva (2002), realizado em uma pastagem de Brachiaria brizantha cv. Marandu, com um ano de formação, o nível de ingestão de suplemento de $1000 \mathrm{~g} \mathrm{dia}^{-1}$, aproximadamente $0,5 \%$ do PV - que corresponde ao nível observado no presente trabalho na época seca $(0,435 \%)$-, imprimiu um diferencial maior de GPV (215 g animal- ${ }^{-1}$ dia $^{-1}$ ), em relação aos $67 \mathrm{~g}$ animal ${ }^{-1} \mathrm{dia}^{-1}$.

Comparando-se o nível de ingestão de nutrientes (PB e NDT), observou-se, no presente trabalho, que os animais consumiram, via suplemento, $168 \mathrm{~g}$ a mais de $\mathrm{PB}$ e 81 g a menos de NDT. Porém, a qualidade do marandu, com mais de $8 \%$ de PB e, aproximadamente $55 \%$ de NDT, na matéria seca foliar (folhas e talos finos verdes), possivelmente contribuiu, de modo significativo, para o diferencial de GPV observado entre os dois trabalhos.

Nas épocas avaliadas, ocorreram resultados diferenciados no ganho de peso vivo dos animais, na época seca a suplementação imprimiu uma diferença significativa entre os ganhos médios, 0,669 x 0,602 kg animal ${ }^{-1} \mathrm{dia}^{-1}$, e esses ganhos foram maiores que os obtidos no período de águas, inclusive com diferença significativa entre épocas, $0,635 \times 0,430 \mathrm{~kg} \mathrm{animal}^{-1} \mathrm{dia}^{-1}$. Dois fatores poderiam explicar esse maior ganho no período de seca, um seria o nível de precipitação registrado nessa época, e o outro seria, segundo Corsi (1993), a possibilidade de ter ocorrido maior disponibilidade de forragem de melhor qualidade no período seco, em relação ao chuvoso, aliada ao maior consumo de suplemento por animal, em relação ao PV observado no presente trabalho, $0,435 \%$ na seca, e $0,265 \%$ nas águas.

Resultado semelhante foi obtido por Lourenço \& Leme (1999): na seca, o GPV dos animais suplementados o ano todo foi de $719 \mathrm{~g}_{\text {animal }}{ }^{-1} \mathrm{dia}^{-1} \mathrm{e}$, nas águas, foi de $592 \mathrm{~g}$; os autores justificam o fato pelas condições excepcionais de precipitação na época de seca e, também, pela adubação nitrogenada, realizada no final das águas.

O ganho do peso médio, durante o ano, para os animais suplementados, foi de $635 \mathrm{~g}_{\text {animal }}{ }^{-1} \mathrm{dia}^{-1}$, em função do consumo individual de suplemento de $756 \mathrm{~g} \mathrm{dia}^{-1}$ (seca) e de $944 \mathrm{~g} \mathrm{dia}^{-1}$ (águas). Esse ganho é superior ao obtido no presente trabalho, que foi de $561 \mathrm{~g}_{\text {animal }}{ }^{-1} \mathrm{dia}^{-1}$. Apesar dos consumos médios diários de suplementos, durante o ano, terem sido iguais, $1.700 \mathrm{~g}$, os consumos nas épocas foram invertidos, isto é, na seca foi de $969 \mathrm{~g} \mathrm{dia}^{-1}$ e nas águas $731 \mathrm{~g} \mathrm{dia}^{-1}$.

Comparando-se as médias anuais de ganho de peso diário, entre os tratamentos, esses autores verificaram que os animais suplementados ganharam $239 \mathrm{~g} \mathrm{dia}^{-1} \mathrm{a}$ mais, do que os que consumiram apenas mistura mineral, resultado superior ao observado no presente trabalho, onde a diferença foi de apenas $57 \mathrm{~g} \mathrm{dia}^{-1}$, apesar dos níveis de PB e NDT dos suplementos serem semelhantes, aproximadamente $45 \%$ e $67,8 \%$ na seca, e $38 \%$ e $67 \%$ nas águas.

Cavaguti et al. (2000) trabalharam somente no período da seca e realizaram um experimento com estrutura semelhante, isto é, suplementação em pasto de Braquiaria decumbens, bezerras mestiças (europeu $\mathrm{x}$ zebu) recém desmamadas, lotação semelhante e rodízio de piquetes para reduzir efeito de pasto.

No tratamento controle, onde foi oferecida apenas mistura mineral completa, o GPV de $148 \mathrm{~g} \mathrm{animal}^{-1} \mathrm{dia}^{-1}$ foi bem abaixo do obtido no presente trabalho, ou seja, $454 \mathrm{~g}_{\text {animal }}{ }^{-1}$ dia $^{-1}$ a menos, provavelmente explicado pela baixa precipitação ocorrida no período.

No tratamento do presente trabalho, com $8 \%$ de uréia, mais farelo de soja e mistura mineral, com $45 \%$ de PB, o qual corresponde ao tratamento de suplementação na época de seca, a diferença no GPV diário continuou a ser alta, $427 \mathrm{~g}$, e poderia estar relacionada com a diferença na quantidade de PB ingerida diariamente, isto é, 
aproximadamente $295 \mathrm{~g}$ a mais. Tal quantidade seria suficiente, segundo o NRC, 1984, para satisfazer as exigências de proteína, para elevar o GPV de uma bezerra com $200 \mathrm{~kg}$, de $200 \mathrm{~g}$ para $1 \mathrm{~kg} \mathrm{dia}^{-1}$, desde que fosse satisfeita, também, a exigência de energia. Os autores concluem que o fornecimento de sal proteinado, NNP + proteína verdadeira, promove um significativo aumento no GPV, quando comparado com o fornecimento de mistura mineral exclusivo ou com uréia.

No presente trabalho, estimou-se que o suplemento utilizado, na época das águas, tinha 39\% de PB (16,50\% de PNDR e 22,50\% de PDR), o que proporcionou um GPV de $454 \mathrm{~g}_{\text {animal }}{ }^{-1}$ dia $^{-1}$ e correspondeu a um ganho adicional, em relação ao grupo testemunha, de $48 \mathrm{~g}$ diárias; o animal ingeriu, via suplemento, 257 g de PB e $109 \mathrm{~g}$ de PNDR. Nessa linha de trabalho, Manella et al. (2002) obtiveram $782 \mathrm{~g}$ animal $^{-1} \mathrm{dia}^{-1}$ de GPV, com um diferencial positivo de $137 \mathrm{~g}$, em relação ao grupo-testemunha, consumo médio de PB igual a 336 g dia-1 , e de PNDR de $124 \mathrm{~g} \mathrm{dia}^{-1}$; os bezerros utilizados nesse experimento tinham peso inicial de $152 \mathrm{~kg}$, tendo permanecido em pasto de braquiarão, com pastejo rotacionado e adubação nitrogenada.

Paulino et al. (1996) consideraram a possibilidade dos bovinos, de responderem ao aumento do suprimento de proteína intestinal, via proteção com tanino. Mbongo et al. (1994) citados por Poppi \& McLennan (1995) afirmaram que são necessárias aproximadamente $150 \mathrm{~g}$ de proteína extra, que sobrepassam para o intestino (PNDR), no sentido de se obter um acréscimo no ganho de peso $300 \mathrm{~g} \mathrm{dia}^{-1}$ animal $^{-1}$, para bezerros de $200 \mathrm{~kg}$, acréscimo este bem superior aos citados, anteriormente, em nosso trabalho, e por Manella et al. (2002), de $48 \mathrm{~g}$ e $137 \mathrm{~g}$, apesar de atenderem $72,7 \%$ e $82,7 \%$, respectivamente, da exigência extra de proteína.

Quanto à suplementação energética (milho) ou energético/protéica (farelo de algodão), na época das águas, com animais em pastejo de Brachiaria decumbens, Paulino et al. (2000) não observaram qualquer efeito, quando avaliaram GPV e rendimento de carcaça; porém, a ingestão de matéria seca, via suplemento, foi de aproximadamente $0,095 \%$ do PV, considerada de baixo nível, provavelmente em conseqüência de pastejo seletivo, permitido pela alta disponibilidade de forragem (9.950 kg ha-1), que foi determinante para o excelente desempenho dos animais (GPV = 1,2 kg animal-1 $\mathrm{dia}^{-1}$ ). Conclusão semelhante foi feita por Zervoudakis et al. (2001) que utilizaram a mes- ma espécie forrageira, com disponibilidade de $6.800 \mathrm{~kg} \mathrm{ha}^{-1}$, mas com ingestão de suplemento maior (0,3\% e $0,6 \%$ do PV).

O trabalho de Milton et al. (1997) conclui que, em alguns casos, a suplementação com PNDR não implica melhores desempenhos, e a justificativa seria a exigência de proteína metabolizável ser atendida pela somatória da proteína microbiana e da proteína de um alimento, por exemplo o milho, que escapa da degradação ruminal. Tal afirmativa está relacionada com o pior desempenho obtido pelos animais, quando alimentados com altos níveis de concentrado e PNDR oriunda de farelo de glúten de milho e farinha de sangue. Essas ponderações estão de acordo com outros pesquisadores como Sindt et al. (1993). Detmann et al. (2001) concluíram que a suplementação de animais, em condições de pasto, com alta disponibilidade de forragem e, portanto, com possibilidade de realizar um pastejo altamente seletivo, causaria diminuição da ingestão de matéria seca total (IMS) (21,2\%), da ingestão de forragem (33,6\%) e, também, da digestibilidade de alguns nutrientes.

Uma avaliação da eficiência da utilização de suplementos, realizada por Manella et al. (2002), apresentou um cálculo de eficiência alimentar ( $\mathrm{kg}$ de GPV kg-1 de concentrado consumido) igual a 1, para suplementação no ano todo, a qual é superior ao obtido no presente trabalho, que foi 0,66 .

Na Tabela 4, é apresentada uma avaliação econômica do presente experimento, que avalia o valor da venda dos animais para abate, e os períodos das secas e águas, distintamente. Observa-se que não houve vantagem econômica com a utilização dos suplementos, quando comparamos esse tratamento com a utilização de apenas uma mistura mineral comercial, de boa qualidade e própria para a categoria de animais em questão. Deve-se considerar, nessa discussão, que o período das

Tabela 4. Avaliação econômica da utilização dos suplementos, nos períodos seco e de águas, por animal.

\begin{tabular}{|c|c|c|c|c|}
\hline \multirow[t]{2}{*}{ Variável } & \multicolumn{2}{|c|}{ Seca (90 dias) } & \multicolumn{2}{|c|}{ Águas (110 dias) } \\
\hline & SPE & MM & SPE & MM \\
\hline GPV (kg) & 60,21 & 54,18 & 49,94 & 44,66 \\
\hline Ingestão $(\mathrm{kg})^{(2)}$ & 87,21 & 6,39 & 80,41 & 8,14 \\
\hline Custo $(\mathrm{R} \$)^{(3)}(\mathrm{C})$ & 36,63 & 4,15 & 52,27 & 5,29 \\
\hline $\operatorname{Receita}(\mathrm{R} \$)^{(4)}(\mathrm{R})$ & 121,06 & 108,94 & 100,41 & 89,80 \\
\hline $\mathrm{R}-\mathrm{C}(\mathrm{R} \$)$ & 84,43 & 104,79 & 48,14 & 84,51 \\
\hline
\end{tabular}

${ }^{(1)}$ Ganho de peso vivo no período. (2)Ingestão dos suplementos no período. ${ }^{(3)}$ Custos dos suplementos e da mistura mineral ingeridas. ${ }^{(4)}$ Valor da arroba $=\mathrm{R} \$ 58,00$; rendimento de carcaça $=52 \%$. 
secas não foi rigoroso, tendo chovido mais de $400 \mathrm{~mm}$, e que a disponibilidade de matéria seca nos piquetes permitiu pastejo seletivo. O retorno econômico, em virtude da composição dos suplementos, principalmente pelo custo do farelo de soja, pode ser considerado baixo e bastante variável, de acordo com a disponibilidade e custo dos alimentos, e estratégia para aquisição dos mesmos.

Pode-se considerar numa avaliação econômica, a antecipação da estação de monta, por causa do melhor desempenho ponderal das fêmeas, em função da suplementação. Nesse sentido, o ANUALPEC (1997) relata que, considerando-se a vida inteira reprodutiva de uma fêmea, o resultado da antecipação da primeira parição, para 24 meses de idade, implica um ganho de 0,7 bezerro, além da diminuição na idade média do rebanho, a diminuição do tempo improdutivo das fêmeas e o maior descarte, em um rebanho estabilizado.

No presente trabalho, tanto o lote de fêmeas suplementadas como o de não-suplementadas, alcançaram os pesos limites para primeira cobertura no mês de dezembro, com idade aproximada de 14 meses, o que possibilitaria que parissem com a idade próxima de 24 meses.

\section{Conclusão}

A suplementação a pasto, de bezerras desmamadas, na época das secas, com proteína degradável no rúmen, e nas águas, com proteína não-degradável no rúmen, não apresentou vantagens bioeconômicas que pudessem recomendar o seu uso.

\section{Referências}

ANUALPEC 97. Anuário da pecuária brasileira. São Paulo: FNP Consultoria \& Comércio, 1997. 329p.

CATON, J.S.; DHUYVETTER, D.V. Influence of energy supplementation on grazing ruminants: requeriments and responses. Journal of Animal Science, v.75, p.533-542, 1997.

CAVAGUTI, E.; ZANETI, M.A.; MORGULIS, S.C.F. Suplementação nitrogenada para bezerras de corte mantidas a pasto no período de estiagem. In: REUNIÃO ANUAL DA SOCIEDADE BRASILEIRA DE ZOOTECNIA, 37., 2000, Viçosa. Anais. Viçosa: Sociedade Brasileira de Zootecnia, 2000. 1 CD-ROM.

CORSI, M. Potencial das pastagens para a produção de leite. In: PEIXOTO, A.M.; MOURA, J.C.; FARIA, V.P. (Ed.). Bovinocultura leiteira: fundamentos da exploração racional. 2.ed. Piracicaba: Fealq, 1993. p.399-411.
DETMANN, E.; PAULINO, M.F.; ZERVOUDAKIS, J.T.; VALADARES FILHO, S.C.; LANA, R.P.; QUEIROZ, D.S. Suplementação de novilhos mestiços durante a época das águas: parâmetros ingestivos e digestivos. Revista Brasileira de Zootecnia, v.30, p.1340-1349, 2001.

EUCLIDES, V.P.B.; EUCLIDES FILHO, K.; ARRUDA, Z.J.; FIGUEIREDO, G.R. Alternativas de suplementação para redução da idade de abate de bovinos em pastagem de Brachiaria decumbens. Campo Grande: Embrapa-CNPGC, 1997. 25p. (Circular Técnica, 25).

GRANDINI, D.V. Produção de bovinos a pasto com suplementos protéicos e/ou energéticos. In: MATTOS, W.R.S.; PIRES, A.V.; HADDAD, C.M.; NUSSIO, L.G. A produção animal na visão dos brasileiros. Piracicaba: Fealq; Sociedade Brasileira de Zootecnia, 2001. p.235-245.

HOOVER, W.H.; MILLER, T.K. Rumen digestive physiology and microbial biology. Virginia: West Virginia University, 1992. 36p. (Agric. Exp. Sta. Bull, 708T).

LOURENÇO, A.J.; LEME, P.R. Desempenho animal em pastagens de Brachiaria brizantha associado a banco de proteína ou suplementação alimentar. In: REUNIÃO DA SOCIEDADE BRASILEIRA DE ZOOTECNIA, 36., 1999, Porto Alegre. Anais. Porto Alegre: Sociedade Brasileira de Zootecnia; Gmosis, [1999]. 1 CD-ROM.

MANELLA, M.Q.; LOURENÇO, A.J.; LEME, P.R. Recria de bovinos Nelore em pastos de Brachiaria brizantha com suplementação protéica ou com acesso a banco de proteína de Leucaena lecocephala: desempenho animal. Revista Brasileira de Zootecnia, v.31, p.22742282, 2002.

MILTON, C.T.; BRANDT JUNIOR, R.T.; TITGEMEYER, E.C.; KUHL, G.L. Effect of degradable and escape protein and roughage type on performance and carcass characteristics of finishing yearling steers. Journal of Animal Science, v.75, p.2834-2840, 1997.

MINSON, D.J. Forage in ruminant nutrition. New York: Academic Press, 1990. 483p.

NATIONAL RESEARCH COUNCIL (Washington, DC). Nutrient requirements of beef cattle. 6.ed. Washington: National Academy Press, 1984. 90p.

PAULINO, M.F.; BORGES, L.E.; CARVALHO, P.P.; FREITAS, R.T.F. Fontes de proteína em suplementos múltiplos sobre o desenvolvimento de novilhos e novilhas mestiços em pastoreio durante a época das águas. In: REUNIÃO ANUAL DA SOCIEDADE BRASILEIRA DE ZOOTECNIA, 33., 1996, Fortaleza. Anais. Fortaleza: SBZ, 1996. v.1. p.12-14.

PAULINO, M.F.; KABEYA, K.S.; VALADARES FILHO, S.C.; PEREIRA, O.G. Suplementação de novilhos mestiços em pastagem de Brachiaria decumbens durante o período das águas. In: REUNIÃO ANUAL DA SOCIEDADE BRASILEIRA DE ZOOTECNIA, 37., 2000, Viçosa. Anais. Viçosa: Sociedade Brasileira de Zootecnia, 2000. 1 CD-ROM.

PAULINO, M.F.; RECHFELD, O.A.M.; RUAS, J.R.M. Alguns aspectos da suplementação de bovinos de corte em regime de 
pastagem durante a época seca. Informe Agropecuário, v.8, p.2831, 1982.

POPPI, D.P.; McLENNAN, S.R. Protein and energy utilization by ruminants at pasture. Journal of Animal Science, v.73, p.278290, 1995.

SINDT, M.H.; STOCK, R.A.; KLOPFENSTEM, T.J.; SHAIN, D.H. Effect of protein source and grain type on finishing calf performance and ruminal metabolism. Journal of Animal Science, v.71, p.10471056, 1993.
THIAGO, L.R.L.S.; SILVA, J.M. Suplementação a pasto: uma estratégia necessária para a produção do novilho precoce. In: DIA DE CAMPO SOBRE PARDO-SUÍÇO CORTE, 2002, Campo Grande. Anais eletrônicos. Campo Grande: Embrapa-CNPGC, 2002. Disponível em: <http://www.cnpgc.embrapa.br/eventos/2002/ dcpardo/index.html> . Acesso em: 4 abr. 2003.

ZERVOUDAKIS, J.T.; PAULINO, M.F.; DETMANN, E. Desempenho e características de carcaça de novilhos suplementados no período das águas. Revista Brasileira de Zootecnia, v.30, p.13811389, 2001.

$\overline{\text { Recebido em } 5 \text { de fevereiro de } 2004 \text { e aprovado em } 22 \text { de fevereiro de } 2005}$ 